\title{
A systematic mapping about simulators and remote laboratories using hardware in the loop and robotic: Developing STEM/STEAM skills in pre-university education
}

\author{
Nibeth Mena Mamani \\ GRIAL Research Group InterAction \\ and eLearning of Salamanca \\ University \\ Salamanca, Spain \\ nmena@usal.es
}

José Gonçalves

Instituto Politécnico de Bragança

Bragança, Portugal

goncalves.jllima@ipb.pt

\author{
Francisco José García-Peñalvo \\ Computer Science Department \\ GRIAL Research Group InterAction \\ and eLearning of Salamanca \\ University \\ Salamanca, Spain \\ fgarcia@usal.es
}

\author{
Miguel Á. Conde \\ University of Leon \\ Escuela de Ingenierías, Campus de \\ Vegazana S/N, León 24071. \\ Leon, Spain \\ mcong@unileon.es
}

\begin{abstract}
In recent years and after the strong impact of the last global health emergency (COVID-19) information and communication technologies have had a great impact on society but particular in the teaching-learning process. Education has been impacted at all its levels. Therefore, education models have been to be adapted to this new challenging paradigm by using different tools such as videoconferences, simulations, on-line interactive applications, virtual and remote laboratories, robots, etc.
\end{abstract}

The objective of this work is to elaborate a systematic mapping to know what scientific from its beginning to 2020, identifying the most literature exists regarding simulators, remote and virtual laboratories focused on STEM/STEAM skills development in the educational context. To do so, bibliographical data gathered of four of the most popular and complete electronic databases (ACM, IEEE, Scopus and Web of Science). At the begging we selected 1232 articles after applying the acceptance criteria defined as part of the search and select strategy, we had 61 articles that help us to answer some questions like what are the most popular virtual and remote labs? or what are the current trends and issues of these tools? and the future ones?

Keywords- Education, STEM/STEAM, Hardware in the loop, Remote laboratory, virtual laboratory

\section{INTRODUCTION}

In recent years, remote laboratories have become an increasingly common practice, especially in science and engineering education [1-3]. In the context of education, remote laboratories can be beneficial for students, teachers, and educational institutions because students can organize their learning process to suit their needs, as they can do their laboratory work anywhere, and anywhere. That can create a feeling of autonomy which contributes to motivation.

Education in the areas of Science, Technology, Engineering, and Mathematics (STEM) [4-6] and adding the study of arts to that equation extends the acronym to STEAM [7-8] is recognized as one of the top priorities for school education worldwide and inquiry-based teaching and learning is identified as a promising approach. To effectively engage students in research tasks, proper guidance must be provided by combining digital tools such as virtual labs, remote, and digital tools.

The use of laboratories in education is a key element, and it becomes more important especially in the paradigm of distance education due to the difficulties that it entails.

As the author Guinaldo [10] states that online laboratories in education are gaining importance, therefore digital resources are invaluable considering their uses in education and research areas. That is why there is a huge set of labs and software like HOME I / O [8]. Many virtual and remote labs can help you achieve your teaching/research goals. However, in some cases finding the perfect solution for a particular system is very difficult. So, there are investigations that present architecture or design for the creation of online laboratories such as [11] and [12]. It is also important to analyze and evaluate the result of the use of the laboratories. In this aspect Brinson [1] was able to demonstrate that the learning results were equal or better in non-traditional laboratories (remote and virtual) than in traditional ones (practical) after an empirical review.

Therefore, the aim of this review is to investigate the existing scientific literature on simulators, remote or virtual laboratories that offer hardware in the loop or robots for the development of STEM/STEAM skills. Thus, we investigated the following research questions: How many studies were published on simulators or remote laboratories within the STEM/STEAM educational context? What types of laboratories did the different studies use? What instruments were used to evaluate remote laboratories or simulators? What are the current trends that the authors present? What are the future challenges that the authors present?

This document is structured as follows: Section II describes the research method followed to perform the systematic mapping. Section III describes the data extraction process to analyze the selected articles. Section IV presents the results of the systematic mapping, ending with Section V where the results are discussed and finally, in Section VI the conclusions of the work are presented. 


\section{RESEARCH METHOD}

A systematic mapping of the literature is a method with scientific value to interpret the information posted in relation to a topic and that is guided by means of research questions. The study was carried out following the process described in [13-14] for making mapping and systematic reviews. The systematic mapping presents three main stages, in the first stage the planning, in which the main objectives and the research questions to be answered are defined, the second stage generates the search strategy, the selection, evaluation, and extraction of data from selected articles. The final stage is the reporting phase, where the results obtained that answer the questions posed in the first stage are presented.

\section{A. Research questions}

The aim of the research of this systematic mapping is to investigate the existing scientific literature on simulators or remote or virtual laboratories that offer hardware in the loop or robots for the development of STEM/STEAM skills. Therefore, systematic mapping aims to respond to:

MQ1.How many studies were published on simulators or remote labs that offer hardware in the loop?

MQ2. What simulators or remote labs do studios offering hardware in the loop mention?

MQ3. What instruments were used to evaluate remote laboratories or simulators?

MQ4. What are the current trends that the authors expose?

MQ5. What are the future challenges for the authors?

\section{B. Inclusion and exclusion criteria}

The article selection criteria are defined that will allow to rule out irrelevant studies on the search results. A set of inclusion criteria (CI) and a set of exclusion criteria (CE) were designed. The study selection was not based on any range of article publications. All articles that met the following inclusion criteria were included in the review.

CI 1: The article indicates the use of laboratories or remote simulators to access hardware in the loop or robotics.

CI 2: The article presents the use of laboratories or simulators to develop STEM/ STEAM skills.

CI 3: The full text of the article is available.

CI 4: The articles were published in journals.

CI 5: The article is written in English.

Articles were excluded if the following criteria were met:

CE 1: The article does not mention the use of remote/simulators laboratories that offer hardware in the loop or robotics.

CE 2: The article does not guide the use of remote/simulators laboratories to develop STEM/STEAM skills

CE 3: The full text of the article is not available.

CE 4: The article was not published in a journal.

CE 5: The article is not written in English.

\section{Search strategy}

The first step to extract the relevant articles for this work was the selection of the databases electronic. In this case, four of the most popular and complete databases were selected according to the research context, which are:
- ACM Digital Library (https://dl.acm.org).

- IEEE Digital Library (https://ieeexplore.ieee.org/).

- Scopus (https://www.scopus.com/).

- Web of Science (www.webofknowledge.com).

The reason to use these databases is because are the most valued ones in an information and communications technology (ICT) context, also provide a high number of journals and conferences that is safe, accurate, current, validated, copyright and organized.

The base structure of the search base string is composed of:

\section{(SIMULATOR OR REMOTE LAB* OR VIRTUAL LAB*) AND (HARDWARE IN THE LOOP OR ROBOT*)}

\section{DATA EXTRACTION}

First of all, to describe the data extraction, the PRISMA [15] flow diagram shown in Figure 1 was used. Starting with the first stage, the search strings were applied in the different databases, the results obtained were downloaded in BibTeX format and uploaded to the Parsifal tool (https://parsif.al/) in which all the planning and classification of the mapping articles was carried out. The classification of the articles is also stored in a GitHub repository (https://cutt.ly/5hVICrC). Initially the analysis of the exclusion and inclusion criteria in the title, keywords, and abstract of each article made it possible to select the articles having a total of 62 articles part of the systematic mapping.

In summary, a total of 1,232 articles were collected in the first search in the four databases, 872 articles were deleted as duplicates. Once the criteria were applied to the title, abstract, and keywords, 61 articles were included in the systematic mapping. During full-text reviewing of articles found 12 articles following the bibliography references and cited by those articles were added having in total 74 articles, after the full-text revision 13 articles were excluded, so finally there are 61 articles included for systematic mapping.

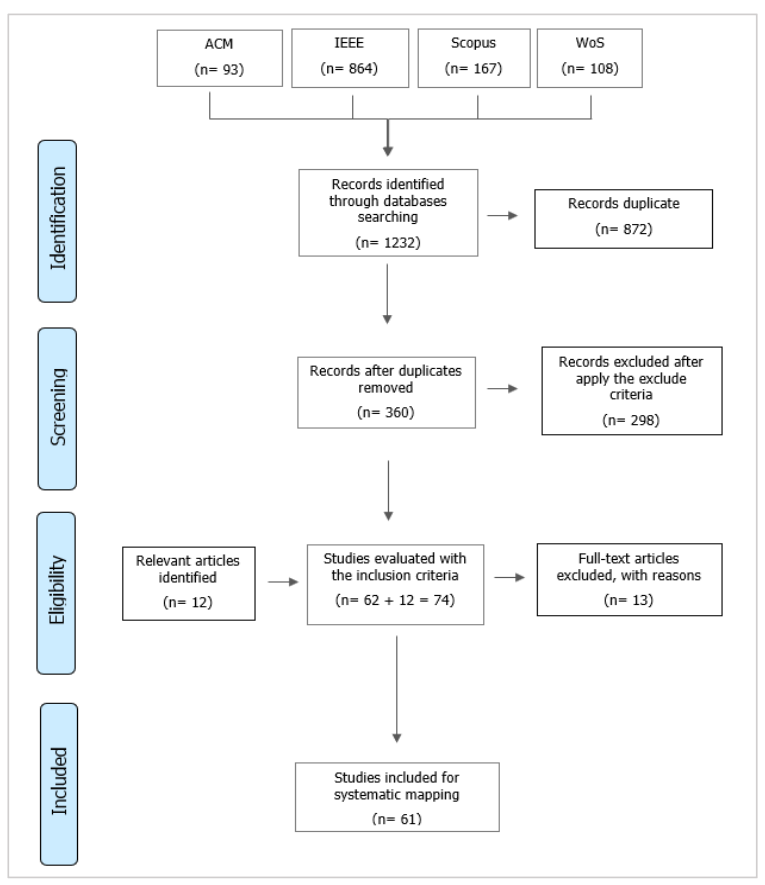

Fig. 1. PRISMA flow chart [15] representation of review phases 


\section{SYSTEMATIC MAPPING RESULTS}

In this section, it starting the analyze of results obtained through mentioned in the search strategy. The information extracted from the selected studies is also used to answer the mapping research questions defined in subsection $A$.

\section{A. MQ1. How many studies were published on simulators} or remote labs that offer hardware in the loop?

The Figure 2 shows the number of publications on simulators or remote laboratories. These articles are those that passed the selection process.

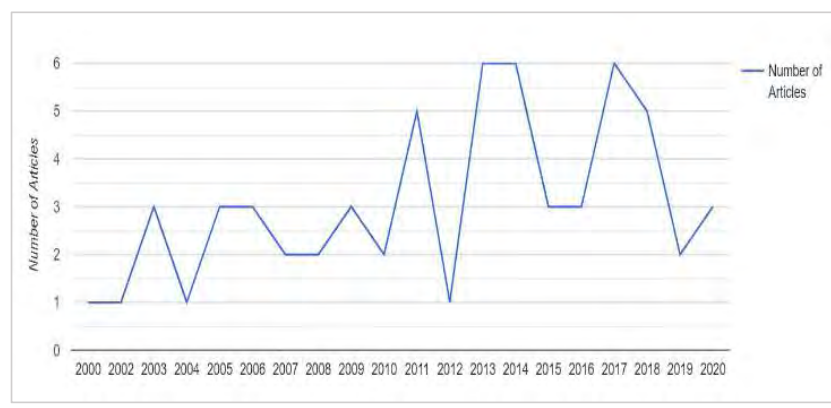

Fig. 2. Published articles per year

B. MQ2. What simulators or remote labs do studios offering hardware in the loop mention?

To answer this question, was analyzed the goals of the 61 articles selected, making a detail check all of them it was possible to identify the virtual or remote labs used. Table I shows the grouping of articles based on the laboratories or remote simulators mentioned in the articles where the most popular labs are MATLAB/ Simulink and also LabVIEW.

TABLE I. ARTICLES GROUPED BY LABORATORY OR SIMULATOR

\begin{tabular}{|l|c|}
\hline \multicolumn{1}{|c|}{ Simulator - Laboratory } & $\begin{array}{c}\text { Total } \\
\text { Articles }\end{array}$ \\
\hline RRC-Lab & 1 \\
\hline MATLAB/Simulink & 15 \\
\hline LabVIEW & 12 \\
\hline Mobile robot & 13 \\
\hline Easy Java Simulations (EJS) & 8 \\
\hline WebLab & 2 \\
\hline LEGO Mindstorms NXT & 8 \\
\hline m-PaRoLa & 1 \\
\hline MindLab2 & 1 \\
\hline WebLab-Deusto RLMS (Remote Laboratory & 2 \\
\hline Management System) & 1 \\
\hline RoboSim & 1 \\
\hline Three-Link Robot & 1 \\
\hline The virtual CVD laboratory & 2 \\
\hline Remote Experimentation Laboratory (RExLab) & 2 \\
\hline RemoteLaboratory & 2 \\
\hline RobotStudio & 1 \\
\hline Virtual Joint Laboratory for Advanced ICT - & 1 \\
\hline VALIP & 1 \\
\hline LABoratory for parallEL robots - LABEL & 1 \\
\hline TeamViewer - RoboExplorer & 1 \\
\hline Remote Triggered Lab - RT Lab & 1 \\
\hline DistanceLab & 1 \\
\hline WebLab-Deusto & 1 \\
\hline RobUALab & 1 \\
\hline Virtual Laboratory for Robotics (VLR) & 1 \\
\hline Robotics \& Automatic Control Telelab (RACT) & 1 \\
\hline CICLOPE ROBOT & 1 \\
\hline RoboLab & 1 \\
\hline Virtual Pendant & 1 \\
\hline Khepera miniature robot & 1 \\
\hline
\end{tabular}

\begin{tabular}{|l|c|}
\hline \multicolumn{1}{|c|}{ Simulator - Laboratory } & $\begin{array}{c}\text { Total } \\
\text { Articles }\end{array}$ \\
\hline TACOM & 1 \\
\hline Networked Virtual Environment (net-VE) & 1 \\
\hline REAL (Remotely Accessible Laboratory) & 1 \\
\hline UniBot Remote Lab & 1 \\
\hline
\end{tabular}

C. MQ 3. What instruments were used to evaluate remote laboratories or simulators?

One of the aims of the present study is to know what virtual or remote labs were used by different 61 studies selected. In that way, also it is interesting to know what instruments were used or selected to evaluate or validated those labs showed in the Figure 3.

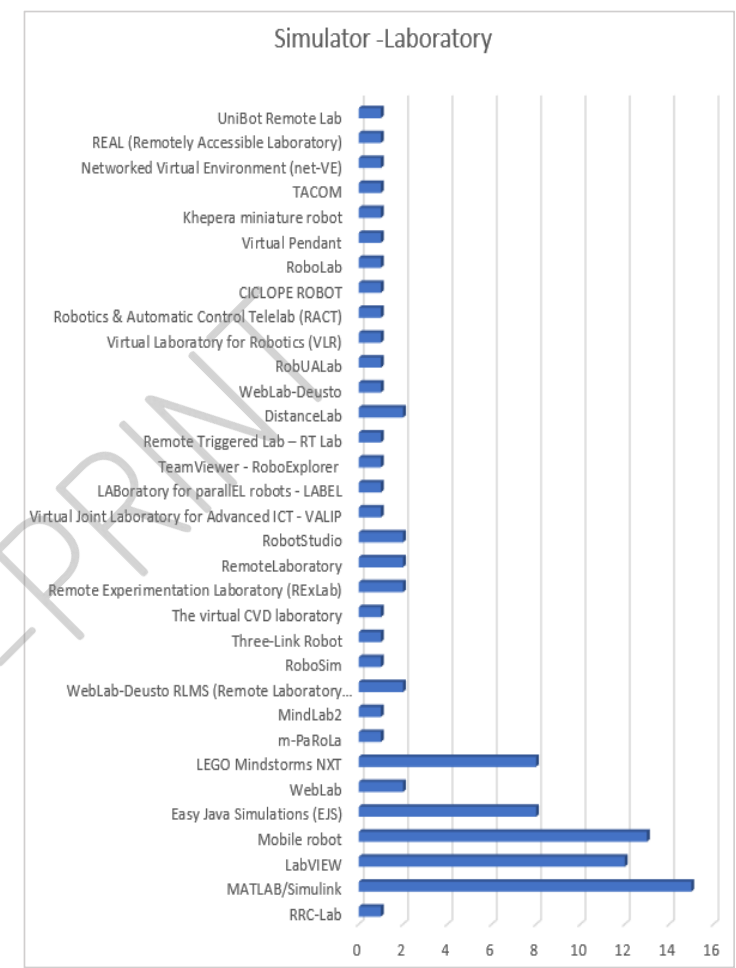

Fig. 3. Articles grouped by laboratory or simulator

Most of the studies used as an instrument the final evaluation and experience of students that used the labs in some training or courses, also the survey as the second option more taking by the authors as it is shown the Figure 4.

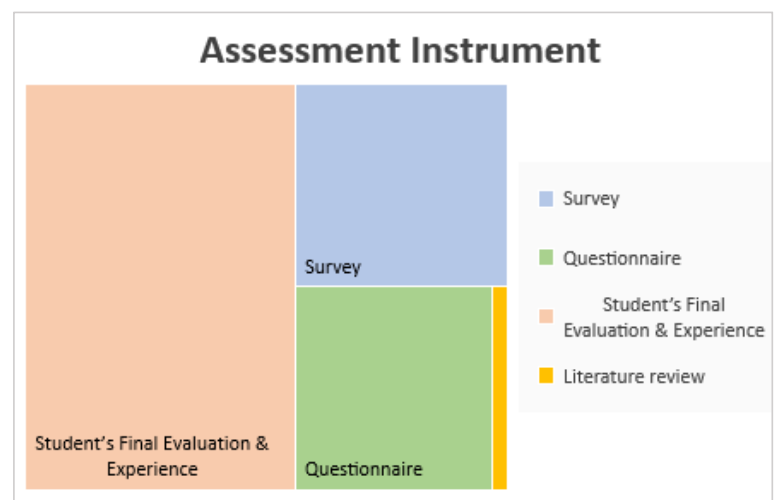

Fig. 4. Articles grouped by assessment instrument 


\section{MQ4. What are the current trends that the authors} expose?

After reviewing the selected articles, it was possible to identify the current trends that the authors are exposing in the different studies. Was a challenge to classify them taking into account that they used different labs.

The Table II shows this classification where the papers reviewed are including new stuffs like sensors, interfaces, software modules, new components or extends to other areas, in the same way they are considering the student experience or feedback about their experience can offering a significant improve of those laboratories.

TABLE II. ARTICLES GROUPED BY CURRENT TRENDS

\begin{tabular}{|l|c|}
\hline \multicolumn{1}{|c|}{ Trends } & $\begin{array}{c}\text { Total } \\
\text { Articles }\end{array}$ \\
\hline $\begin{array}{l}\text { Include new sensors, actuators, laser, chips, } \\
\text { interface elements, software, components, } \\
\text { augmented reality, webcam etc. }\end{array}$ & 22 \\
\hline $\begin{array}{l}\text { Considering the student feedback to improve the } \\
\text { proposal }\end{array}$ & 15 \\
\hline Expand to other areas & 5 \\
\hline Improving the student experience & 25 \\
\hline Used in a teaching environment & 7 \\
\hline Introduce programming & 4 \\
\hline
\end{tabular}

Another point took as a trend is to use these laboratories as teaching environment in different level of education include the introduction of programming to provide a real experience for students and ensure the expected knowledge.

\section{E. MQ5. What are the future challenges for the authors?}

Another interesting case is the classification the future challenges that the authors mentioned in each of their studies. After making the review the challenges identified were classified in 6 groups more popular.

Accordingly, the results are summarized in the Table III. It shows that apply the more experiments, improve the current labs developed or high purchasing, maintenance cost and limited availability are the future challenges that will face the researchers, where the most popular is improve the labs developed integrating in new areas.

TABLE III. ARTICLES GROUPED BY FUTURE CHALLENGES

\begin{tabular}{|l|c|}
\hline \multicolumn{1}{|c|}{ Challenges } & $\begin{array}{c}\text { Total } \\
\text { Articles }\end{array}$ \\
\hline More experiments & 10 \\
\hline $\begin{array}{l}\text { Improve the laboratory developed \& integrated } \\
\text { others areas }\end{array}$ & 26 \\
\hline Create a completely remote lab experience & 23 \\
\hline $\begin{array}{l}\text { High purchasing and maintenance cost and limited } \\
\text { availability. }\end{array}$ & 4 \\
\hline $\begin{array}{l}\text { Find a novel approach } \\
\text { Friendliness, cost and } \\
\text { Improve } \\
\text { compatibility/Complexity }\end{array}$ & 7 \\
\hline
\end{tabular}

\section{DISCUSSIONS}

The computer technology and the Internet have the potential to provide a highly interactive and powerful learning environment for engineering disciplines. Recently, many scholars have put a high attention to the importance of the virtual and remote laboratories which has a huge role that would be played in the field of STEM/STEAM education especially. In other words, the virtual and remote labs have been constantly gaining popularity since their appearance, more these last months with arrived of COVID-19 pandemic [16-20].

In that way exists studies where they are identifying some important priorities related to the design and evaluation [21] and trying to answer to what are their benefits or what are the current trends and issues in the implementation of these tools. They are giving a panoramic view of the main issues of developing and using virtual and remote labs for improving science and engineering education [22-23]. Or proposals of new methods [24] for their personalization and an optimal adaptation of the implementation of virtual and remote labs, likewise, propose the creation of a new mixed hardwaresoftware architecture focused on improving the scalability of those architectures [25].

With the restrictions caused by the COVID-19 pandemic, the teaching in STEM/STEAM has been greatly affected in recent months introducing of distance learning, the teaching remotely using different virtual and remote laboratories also the analysis of the new challenges and possibilities [26]. Thus, the number of papers found in literature addressing virtual and remote laboratories have been increasing quickly. During the reviewing of articles interesting studies were observed oriented to use the virtual or remote labs in the system education. The use of these labs will help to mateine the student performance, interact with the laboratory, learn and understand the practices, the exercises that will developer in the laboratories and help to achieve the teacher's goals. The remote or virtual laboratory should not replace the real robot (in the hands of the students), but complement it and help the teacher during the teaching process. There are several remote laboratories offering robots around the world but with different characteristics [27-28].

There are several virtual and remote laboratory applications aiming for robotics education (Figure 3). Software and hardware platforms in the area commonly use MATLAB/Simulink, LabView, Easy Java Simulations (EJS) and LEGO Mindstorms NX, and often involve mobile robotics to enhance the teaching of basic sensing and intelligent control principles and robotic. Also, they are present different challenges and improvements in the Table II and Table III.

The major challenge in the virtual and remote laboratories appears to be the lack of standardization, impeding the modularity, portability, complexity, compatibility, and scalability of solutions, as well as interoperability between different solutions, the improve the laboratory developed, create the best student experience (Table III). To validate the use of these labs they are use different instruments like survey and the student's final evaluations and experience of use labs.

\section{CONCLUSIONS}

The roles of teachers and students are changing, and there are undoubtedly ways of learning not yet discovered. However, the computer and software technology may provide a significant role to identify the problems, to present solutions and life-long learning. The computer based educational technology has reached the point where many major improvements can be made, and significant cost reductions 
can be achieved, specifically in the area of engineering education. As explained above, STEM/STEAM education possesses many challenges. In the area of automation and control, low-cost computer-based simulation and automated control equipment are para-mount to effective teaching.

In this study 61 articles were identified oriented to use of virtual and remote laboratories. Defined the research questions and answered with the systematic mapping developed, is evident the research in this area is constantly growing more with the COVID-19 lockdown that not only brought negative effects, the new reality and circumstances forced a radical need to rapidly introduce and use all the available technologies and tools for remote, distance work and communication in all contexts. The pandemic of COVID19 has pushed to search for alternatives to the traditionally based learning system of classrooms, halls and laboratories [29-30]. Significantly, it caused a discussion on the need to modernize teaching methods with new technologies and tools as well as to develop completely new organizational concepts [24].

In summary, the virtual and remote laboratories have a strong potential to act as facilitator for supporting collaborations between institutions, teachers, students and researchers worldwide and can have significant contributions to provide in STEM/STEAM education at different levels, ranging from the development of labs, software and experiments to the generation of new technologies put into the use of all organization, institutions, teachers, students and researchers.

\section{REFERENCES}

[1] J. R. Brinson, "Learning outcome achievement in non-traditional (virtual and remote) versus traditional (hands-on) laboratories: A review of the empirical research," Comput. Educ., vol. 87, pp. 218 237, Jul. 2015, doi: 10.1016/j.compedu.2015.07.003

[2] N. Lima, C. Viegas, and F. J. García-Peñalvo, "Different Didactical Approaches Using a Remote Lab: Identification of Impact Factors," Rev. Iberoam. Tecnol. del Aprendiz., Nol. 14, no. 3, pp. 76-86, Aug. 2019, doi: 10.1109/RITA.2019.2942256.

[3] N. M. Lima, M. C. Viegas, and F. J. García-Peñalvo, "Learning from complementary ways of developing experimental competences," Education in the Knowledge Society, vol. 18, no. 1, pp. 63-74, 2017, doi: 10.14201/eks20171816374

[4] M.-S. Ramírez-Montoya, Ed., Handbook of Research on Driving STEM Learning With Educational Technologies. IGI Global, 2017.

[5] C. Ferrada-Ferrada, J. Carrillo-Rosúa, D. Díaz-Levicoy, and F. SilvaDíaz, "Robotics from STEM areas in Primary School: a Systematic Review," Education in the Knowledge Society, vol. 21, 2020, Art no. 22, doi: 10.14201/eks.22036.

[6] F. J. García-Peñalvo, A. Bello, A. Dominguez, and R. M. Romero Chacón, "Gender Balance Actions, Policies and Strategies for STEM: Results from a World Café Conversation," Education in the Knowledge Society, vol. 20, pp. 31-1 - 31-15, 2019, Art no. 31, doi: 10.14201/eks2019_20_a31.

[7] M. Conde, F. J. Rodríguez-Sedano, C. Fernández-Llamas, J. Gonçalves, J. Lima, and F. J. García-Peñalvo, "Fostering STEAM through challenge-based learning, robotics, and physical devices: A systematic mapping literature review," Comput. Appl. Eng. Educ., vol. 29, no. 1, pp. 46-65, Jan. 2021, doi: 10.1002/cae.22354.

[8] E. Hamner and J. Cross, "Arts \& Bots: Techniques for distributing a STEAM robotics program through K-12 classrooms," in ISEC 2013 3rd IEEE Integrated STEM Education Conference, 2013, doi: 10.1109/ISECon.2013.6525207.

[9] B. Riera, F. Emprin, D. Annebicque, M. Colas, and B. Vigário, "HOME I/O: a virtual house for control and STEM education from middle schools to Universities," IFAC-PapersOnLine, vol. 49, no. 6 , pp. 168-173, Jan. 2016, doi: 10.1016/j.ifacol.2016.07.172.
[10] M. Guinaldo, L. De La Torre, R. Heradio, and S. Dormido, "A virtual and remote control laboratory in moodle: The ball and beam system," in IFAC Proceedings Volumes (IFAC-PapersOnline), 2013, vol. 10, no. PART 1, pp. 72-77, doi: 10.3182/20130828-3-UK-2039.00033.

[11] J. Sáenz, L. De La Torre, J. Chacón, and S. Dormido, "A new architecture for the design of virtual/remote labs: The coupled drives system as a case of study," in IEEE International Conference on Emerging Technologies and Factory Automation, ETFA, Sep. 2019, vol. 2019-Septe, pp. 769-775, doi: 10.1109/ETFA.2019.8869192.

[12] A. Visioli and F. Pasini, "A virtual laboratory for the learning of process controllers design," in IFAC Proceedings Volumes (IFACPapersOnline), Jan. 2006, vol. 7, no. PART 1, pp. 458-462, doi: 10.3182/20060621-3-es-2905.00079.

[13] A. García-Holgado, S. Marcos-Pablos, and F. García-Peñalvo, "Guidelines for performing Systematic Research Projects Reviews," Int. J. Interact. Multimed. Artif. Intell., vol. 6, no. 2, p. 9, 2020, doi: 10.9781/ijimai.2020.05.005.

[14] K. Petersen, S. Vakkalanka, and L. Kuzniarz, "Guidelines for conducting systematic mapping studies in software engineering: An update," in Information and Software Technology, Aug. 2015, vol. 64, pp. 1-18, doi: 10.1016/j.infsof.2015.03.007.

[15] D. Moher, A. Liberati, J. Tetzlaff, and D. G. Altman, "Preferred reporting items for systematic reviews and meta-analyses: The PRISMA statement," Int. J. Surg., vol. 8, no. 5, pp. 336-341, 2010, doi: 10.1016/j.ijsu.2010.02.007.

[16] S. J. Daniel, "Education and the COVID-19 pandemic," Prospects, vol. 49, no. 1-2, pp. $91-96$, Oct. 2020, doi: 10.1007/s11125-020-09464-3.

[17] F. J. García-Peñalvo, and A. Corell, "La COVID-19: ¿enzima de la transformación digital de la docencia o reflejo de una crisis metodológica y competencial en la educación superior?" Campus Virtuales, 2020. Vol. 9, no. 2, pp. 83-98.

[18] F. J. García-Peñalvo, "Digital Transformation in the Universities: Implications of the COVID-19 Pandemic," Education in the Knowledge Society, vol. 22, 2021, Art no. e25465, doi: 10.14201/eks.25465.

[19] F. J. García-Peñalvo, A. Corell, V. Abella-García, and M. Grande, "Online assessment in higher education in the time of COVID-19," Educ. Knowl. Soc., vol. 21, pp. 1-26, 2020, doi: 10.14201/eks.23013.

[20] F. J. García-Peñalvo, A. Corell, V. Abella-García, and M. Grande-dePrado, "Recommendations for Mandatory Online Assessment in Higher Education During the COVID-19 Pandemic," in Lecture Notes in Educational Technology, Springer Science and Business Media Deutschland GmbH, 2021, pp. 85-98.

[21] C. S. Tzafestas, "Web-Based Laboratory on Robotics: Remote vs. Virtual Training in Programming Manipulators," in Web-Based Control and Robotics Education, Dordrecht: Springer Netherlands, 2009, pp. 195-225.

[22] R. Heradio, L. de la Torre, and S. Dormido, "Virtual and remote labs in control education: A survey," Annual Reviews in Control, vol. 42. Elsevier Ltd, pp. 1-10, Jan. 01, 2016, doi: 10.1016/j.arcontrol.2016.08.001.

[23] J. Ma and J. V. Nickerson, "Hands-on, simulated, and remote laboratories: A comparative literature review," ACM Comput. Surv., vol. 38, no. 3, p. 1, Sep. 2006, doi: 10.1145/1132960.1132961.

[24] T. O. Almeida and J. F. De Magalhaes Netto, "Adaptive Educational Resource Model to Promote Robotic Teaching in STEM Courses," in Proceedings - Frontiers in Education Conference, FIE, Oct. 2019, vol. 2019-Octob, doi: 10.1109/FIE43999.2019.9028417.

[25] A. Villar-Martinez, L. Rodriguez-Gil, I. Angulo, P. Orduna, J. GarciaZubia, and D. Lopez-De-Ipina, "Improving the Scalability and Replicability of Embedded Systems Remote Laboratories through a Cost-Effective Architecture," IEEE Access, vol. 7, pp. 164164164185, 2019, doi: 10.1109/ACCESS.2019.2952321.

[26] A. S. Alves Gomes, J. F. Da Silva, and L. R. De Lima Teixeira, "Educational Robotics in Times of Pandemic: Challenges and Possibilities," in 2020 Latin American Robotics Symposium, 2020 Brazilian Symposium on Robotics and 2020 Workshop on Robotics in Education, LARS-SBR-WRE 2020, Nov. 2020, doi: 10.1109/LARS/SBR/WRE51543.2020.9307145.

[27] C. P. Antonio, J. P. C. De Lima, J. Bosco Da Motaalves, R. Marcelino, J. Bento Da Silva, and J. P. S. Simao, "Remote experiments and 3D virtual world in education," in exp.at 2015 - 3rd Experiment International Conference: Online Experimentation, Apr. 2016, pp. 6570, doi: 10.1109/EXPAT.2015.7463216. 
[28] T. U. Islamgozhayev, S. S. Mazhitov, A. K. Zholmyrzayev, and E. T. Toishybek, "IICT-bot: Educational robotic platform using omnidirectional wheels with open source code and architecture," in 2015 International Siberian Conference on Control and Communications, SIBCON 2015 - Proceedings, Jul. 2015, doi: 10.1109/SIBCON.2015.7147079.
[29] A. E. E. Sobaih, A. M. Hasanein, and A. E. A. Elnasr, "Responses to COVID-19 in Higher Education: Social Media Usage for Sustaining Formal Academic Communication in Developing Countries," Sustainability, vol. 12, no. 16, pp. 1-18, 2020.

[30] U. Kaden, "COVID-19 School Closure-Related Changes to the Professional Life of a K-12 Teacher," Educ. Sci., vol. 10, 2020, doi: 10.3390/educsci10060165.

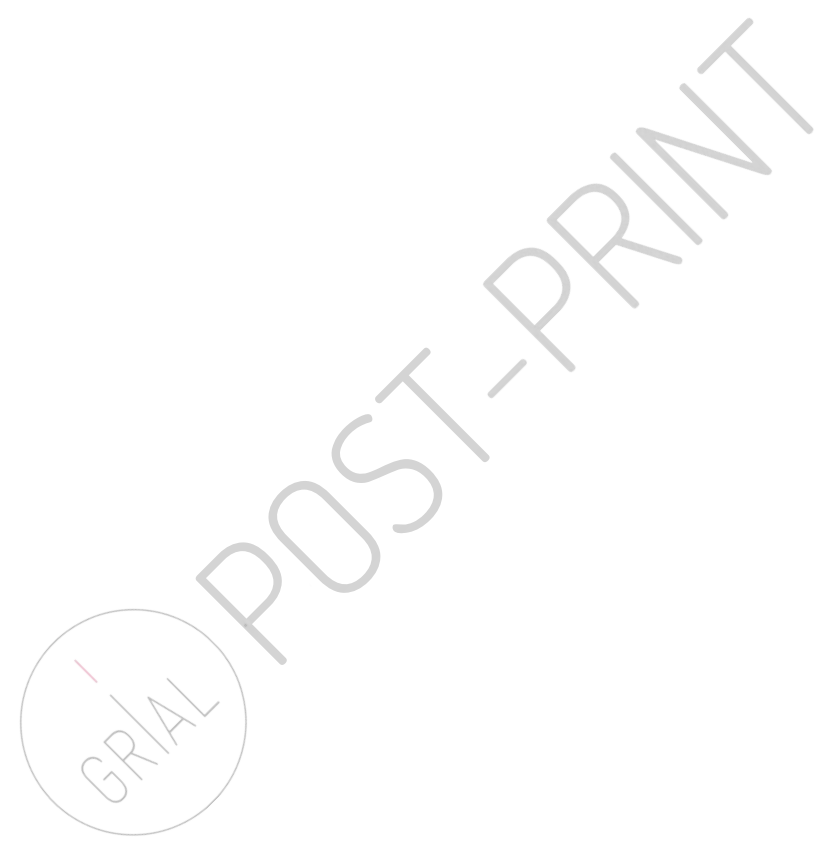

